\title{
Use of insulin glargine and cancer incidence in Scotland: a study from the Scottish Diabetes Research Network Epidemiology Group
}

The SDRN Epidemiology Group

Published online: 3 September 2009

(C) Springer-Verlag 2009

\section{Erratum to: Diabetologia}

DOI 10.1007/s00125-009-1453-1

We wish to correct an error introduced during the typesetting of the paper. The authorship should simply have read The SDRN Epidemiology Group with H. M. Colhoun being the author for correspondence.

The online version of the original article can be found at http://dx.doi. org/10.1007/s00125-009-1453-1.

The SDRN Epidemiology Group University of Dundee, Diabetes Support Centre,

Level 8, Ninewells Hospital,

Dundee, DD1 9SY, Scotland, UK

e-mail: h.colhoun@cpse.dundee.ac.uk 